\title{
A WEB NA RESOLUÇÃO DE DESAFIOS DE PROGRAMAÇÃO: O QUE DIZEM OS ESTUDANTES UNIVERSITÁRIOS SOBRE SUA EXPERIÊNCIA
}

\author{
DANIELA DUARTE DA SILVA BAGATINI ${ }^{1}$ \\ ORCID: https://orcid.org/0000-0001-8548-5841 \\ MARIA CRISTINA VILLANOVA BIASUZ ${ }^{2}$ \\ ORCID: https://orcid.org/0000-0003-4869-389X
}

\begin{abstract}
RESUMO: Esta pesquisa na área da educação e das novas tecnologias desdobra-se em dois caminhos investigativos: a ação do estudante e a operação do meio. A partir da experiência revelada no cenário da prática de programação da disciplina de Estrutura de Dados apoiada pela Web, que disponibiliza as soluções de programação, gera-se uma discussão sobre a questão da cópia, devido ao ambiente compelidor da Web que incrementa os processos da busca online. O texto apresenta trabalhos que discutem o plágio do código-fonte e o efeito descalibrado do próprio conhecimento promovido pelo acesso a Web. Faz-se uma discussão sobre o significado e o processo da experiência amparada em autores como Dewey (1976, 1978, 1980), Larrosa (2002, 2018), Cupani (2013) e McLuhan (1964). A análise de dados realizada através de um questionário aplicado com estudantes universitários ( $\mathrm{n}=149$ respostas) evidencia a experiência Web na resolução de problemas de programação. Como resultado os estudantes declaram a importância, satisfação e relevância da Web para seu estudo.
\end{abstract}

Palavras-chave: experiência Web, estrutura de dados, programação.

\section{THE WEB IN SOLVING PROGRAMMING CHALLENGES: WHAT COLLEGE STUDENTS SAY ABOUT THEIR EXPERIENCE}

\begin{abstract}
This research in the field of education and new technologies unfolds into two investigative ways: student action and online environment working processes. Based on the experience revealed in the programming scenario of the Web-supported Data Structure discipline, the discussion of copy emerges as we consider that the Web presents programming solutions in a compelling and easy-to-reach environment. This paper presents works which discuss the code plagiarism and the uneven knowledge constructed by accessing the Web. It also debates about the meaning and process of the experience based on authors like Dewey (1976, 1978, 1980); Larrosa (2002, 2018); Cupani (2013) and McLuhan (1964). Data analysis was performed based on a questionnaire applied to college students ( $\mathrm{n}=149$ answers) and

\footnotetext{
1 Programa de Pós-Graduação em Informática na Educação (PPGIE) da Universidade Federal do Rio Grande do Sul (UFRGS). Porto Alegre, RS, Brasil. <danielabagatini@gmail.com>

2 Programa de Pós-Graduação em Informática na Educação (PPGIE) da Universidade Federal do Rio Grande do Sul (UFRGS). Porto Alegre, RS, Brasil. <cbiazus@ufrgs.br> 
it evidences the Web experience in solving programming problems. As a result, students state the importance, satisfaction, and relevance of the Web for their study.

Keywords: Web experience, data structure, programming.

\section{LA WEB PARA RESOLVER LOS DESAFÍOS DE PROGRAMACIÓN: LO QUE DICEN LOS ESTUDIANTES UNIVERSITARIOS SOBRE SU EXPERIENCIA}

RESÚMEN: Esta investigación en el área de la educación y las nuevas tecnologías se desdobla en dos caminos de estudio: la acción del estudiante y los procesos de trabajo del entorno en línea. Con base en la experiencia en el escenario de programación de la disciplina de Estructura de datos respaldada por la Web, surge la discusión sobre la copia cuando consideramos que la Web presenta soluciones de programación en un entorno compulsivo y de fácil acceso. El texto presenta trabajos que discuten el plagio del código fuente y el efecto desequilibrado del conocimiento promovido por el acceso a la Web. Se hace una discusión sobre el significado y el proceso de la experiencia respaldada por autores como Dewey (1976, 1978, 1980); Larrosa (2002 2018); Cupani (2013) y McLuhan (1964). El análisis de datos realizado a través de un cuestionario aplicado a estudiantes universitarios $(n=149$ respuestas) destaca la experiencia Web en la resolución de problemas de programación. Como resultado, los estudiantes declaran la importancia, satisfacción y relevancia de la Web para su estúdio.

Palabras clave: experiencia Web, Estructura de Datos, programación. 


\section{INTRODUÇÃO}

"Se não está na Internet, não existe, professora! Então, não perdemos tempo". Que significado tem a fala deste estudante para um professor? Dita por um estudante universitário da disciplina de Estrutura de Dados (unidade que compõe o currículo de Computação), a fala é aparentemente despretensiosa, mas com um potencial enorme para reflexão. Desenvolvemos, utilizamos e enxergamos na tecnologia tantos proveitos para a nossa vida que, por vezes não nos parece necessário refletir sobre qualquer outro efeito que possa provocar. Segundo Bannell (2017) na educação as vantagens da tecnologia são tantas e inegáveis que não é difícil adicionar novos itens à lista de utilidades. No entanto, ressalta o autor que "[...] uma coisa é transferir tarefas cognitivas para a máquina ou facilitar a cognição distribuída. Outra é deixar, de um jeito ou de outro, a cargo de máquinas a direção do processo de aprendizagem.” (BANNELL, 2017, p.36).

No contexto da conexão tecnológica, a Web mobiliza relevantes discussões sobre o seu uso e como instrumento educacional no apoio a projetos de aula. Também, põe em pauta o debate sobre a procedência de uma informação e até memso sobre a falta de clareza da autoria. Este tema, por sinal, leva a outras críticas recorrentes dos professores da área de Computação: a cópia do código-fonte (instruções escritas através de palavras e símbolos em uma linguagem de programação) e a origem de um software.

Por mais poêmicas na ordem da ética ou da autoria coletiva que possamos traçar sobre o uso de artefatos tecnológicos digitais na educação - e chamamos a atenção para o fato de que a Web é o recurso mais utilizado na educação, portanto, deveríamos dedicar nossas pesquisas a ela a partir de diferentes abordagens -, existem componentes invisíveis desta relação que necessitamos abarcar, como seus aspectos contextuais, reforçadores e recompensadores (POWERS, 2012; SOARES et al., 2018). Assim, faz-se necessário ampliar as fontes de pesquisa sobre o processo da experiência com a Web, especificamente na resolução de problemas de programação, bem como, fornecer uma visão crítica do uso das tecnologias para as áreas de Computação e Educação.

A questão abordada neste estudo surge a partir do momento em que o estudante tem que resolver um problema de programação, a preferência de alguns é procurar uma solução que esteja disponível na Web. O movimento de busca é, por vezes, um processo automático, imediato, tão eminente quanto o propósito final a que se destina: o desenvolvimento e a resolução. No cenário da disciplina de Estrutura de Dados, o estudante tem por desafio propor soluções para problemas computacionais que resultem em um software, mas antes disso, a resolução significa um processo a enfrentar. Os passos desta resolução revelam o desenvolvimento do processo. Se o caminho escolhido pelo discente inclui o uso da Web e, de certa forma, uma dependência desta como fonte para obter a solução, temos uma questão de valor educativo. Este aspecto é a preocupação inicial que autores como John Dewey $(1976,1978,1980)$, Jorge Larrosa (2002, 2018), Alberto Cupani (2013) e Marshall McLuhan (1964) ajudam a entender.

O foco de discussão não é apenas solucionar um problema, mas resolvê-lo por meio de um processo que permita ao estudante de Computação refletir, considerar a sua posição técnica, ética e estética na produção. Tudo isso implica reconhecer o valor educativo da experiência vivida de programação com a Web que este trabalho visa explorar.

Este artigo inicia com a discussão do referencial teórico e a apresentação de trabalhos relacionados. A seção metodologia trata do método, os procedimentos de trabalho e a coleta de dados com estudantes de Estrutura de Dados sobre a experiência Web na resolução de problemas de programação. Na continuação são apresentados os resultados do estudo e discussões. Por fim, as conclusões seguidas das referências bibliográficas.

\section{REFERENCIAL TEÓRICO}

Para conduzir-nos a uma reflexão sobre experiências com o uso da Web na educação, especialmente na resolução de problemas de programação, e para ilustrar o contínuo desta experiência enquanto um processo que se estabelece, trazem-se os autores Dewey (1976, 1978 e 1980) e Larrosa $(2002,2018)$. Entende-se que nos dias de hoje pensar na prática do estudo fora do contexto da Web é tratar de forma isolada a situação, fora do contexto da experiência. 
Para Dewey (1976 e 1978) o estudante deve ser capaz de investigar, deliberar entre as alternativas concorrentes e orientar-se na direção do desenvolvimento. Em pauta, portanto, a importância da experiência enquanto processo, a partir de um entendimento científico - levantar informações sobre o problema, pesquisar, articular e testar possibilidades de solução para chegar a uma resposta - e, também, uma atitude estética. De acordo com o autor, nem toda experiência é educativa, por vezes, pode ser agradável, no entanto concorrer para atitudes descuidadas e preguiçosas, atuando sobre a qualidade das experiências posteriores (DEWEY, 1976).

Para Larrosa (2002) o sujeito moderno se relaciona com o acontecimento do ponto de vista da ação e põe a sua existência no fazer coisas. O autor dedica atenção para as circunstâncias que levam a experiência tornar-se cada vez mais rara quando diz "porque sempre estamos querendo o que não é, porque estamos sempre em atividade, porque estamos sempre mobilizados, não podemos parar. E, por não podermos parar, nada nos acontece." (LARROSA, 2002, p.24). No decorrer de suas obras, Larrosa (2018, p.442) transfere a ênfase da palavra "experiência" para a expressão "exercício". O exercício enquanto técnica para formação da atenção em meio à estrutura dos dispositivos atencionais. Nesta perspectiva, o exercício corresponde a "aprender a distinguir o que vale a pena prestar atenção e, uma vez distinguido, escolhê-lo, elegê-lo, atender a ele" (LARROSA, 2018, p.287).

Reafirmando o exposto anteriormente, Dewey (1976), argumenta que cada experiência atua em certo grau sobre as condições objetivas - sejam reguladas pelo educador ou não - e internas onde decorrerão novas experiências. Então, o tipo de experiência vivida pode afetar de forma positiva ou não as atitudes que irão contribuir para a qualidade das experiências subsequentes. Quanto a isto, Dewey comenta que "o problema não é a falta de experiências, mas o caráter dessas experiências" e complementa: "em relação ao efeito de uma experiência, a situação constitui um problema para o educador" (DEWEY, 1978, p.16).

Cupani (2013) fornece pistas sobre o modo como o saber tecnológico e suas produções influenciam a sociedade a que se incorporam, modificando sua cultura e, por conseguinte, a personalidade dos seus membros. $\mathrm{O}$ autor nos orienta a compreender as consequências da tecnologia quando tratada de maneira descuidada. Segundo o autor a tecnologia apresenta uma realidade polifacetada em termos de objetos, sistemas, processos e modos de proceder. Toda realização tecnológica está associada a algum tipo de valoração, seja positiva ou negativa. Soma-se também o fato de que a utilização de objetos e processos técnicos requer um comportamento específico, conforme regras.

Alguns aspectos relatados por Cupani (2013) sobre as consequências da tecnologia nas culturas que influenciam na educação discutem que:

(1) quando a tecnologia dita os fins, menos estes são analisados e discutidos, mais se busca aperfeiçoar os meios de forma que se tem "a atenção ao como, mais do que o porquê das ações, e a obediência aos peritos (qualquer que seja a sofisticação das suas tarefas)" (CUPANI, 2013, p.189);

(2) o conhecimento fica reduzido à informação para resolver problemas e a compreensão do mundo na busca de dados. Isto influencia no entendimento de outros fatores como: o saber dá lugar a acumular informação, a liberdade apresenta-se como modo técnico de agir, a inteligência como capacidade de organizar meios em relação a fins e, a aprendizagem como condicionamento ou acúmulo de dados. Por fim, ciência como pesquisa guiada pela tecnologia - "tecnociência", termo utilizado pelo autor - a espera de resultados úteis (CUPANI, 2013, p.193-194);

(3) a experiência humana é modificada em todos seus aspectos. A capacidade de ação libera o homem de tarefas, "mas ao fazer isso o descentra, distrai e dissipa, o exime de compromissos específicos, de disciplina e do desenvolvimento de determinadas habilidades" (CUPANI, 2013, p.195).

Sendo as tecnologias extensões do nosso corpo, como afirma McLuhan (1964, 1977), o interesse antes pelo seu efeito é mais forte do que o conteúdo que carrega. Ao estender parte de nós ao mundo exterior, a tecnologia pode alterar a maneira como percebemos e processamos a realidade. Para McLuhan, habitamos uma realidade moldada fundamentalmente por nossas ferramentas e influenciada 
por elas. O autor salienta nossa responsabilidade e capacidade de controlar a tecnologia entendendo como ela nos afeta. Sugere a necessidade de prestarmos mais atenção neste processo e decidir o que realmente importa.

Portanto, a educação requer que se preste mais reparo à mídia em uso, no sentido de ter consciência da natureza da operação. Os autores ajudam a visualizar a forma como o espaço Web se apresenta para nós e a perceber como podemos alimentar efeitos benéficos e neutralizar adversos (CUPANI, 2013; DEWEY, 1976, 1978, 1980; LARROSA, 2002, 2018; MCLUHAN, 1964, 1977). Se a tecnologia "nos importa", como afirma Cupani (2013, p.11), é necessário pensar sobre sua presença em nossa vida de modo sistemático, com entusiasmo, mas também com certa cautela. Logo, ter consciência da operação dos elementos da experiência (como tempo, organização, costumes e protocolos) é ser capaz de ditar a qualidade das experiências vividas.

A relação do estudante com o espaço Web pode se revelar educativa, e transformar-se em capacidade de aprender pela experiência. Espera-se que toda experiência possa contribuir para o preparo da pessoa em experiências posteriores de qualidade mais ampla e mais profunda. Isto é o sentido de crescimento, continuidade, reconstrução da experiência de Dewey. Consequentemente, cabe ao educador aproveitar positivamente as possibilidades que oferece a tecnologia, fazer as conexões necessárias, desvelar novos territórios de ação, perceber elos e estabelecer, com responsabilidade, as condições adequadas que dão à experiência presente o seu sentido construtivo.

\section{TRABALHOS RELACIONADOS}

Seguimos a continuação por dois caminhos tomados como desdobramentos de investigação: a Autoria - Cópia, apropriação da solução e direitos autorais; e a Experiência Web - Busca, benefícios imediatos. Consideramos que ambos são relevantes na manutenção do equilíbrio e ponderação para a argumentação. Assim, o arranjo dessa discussão nos permite formular o objeto de pesquisa a partir de um olhar interdisciplinar.

\section{A Autoria-Cópia}

$\mathrm{Na}$ área da Computação, trabalhos científicos dedicam-se a apresentar modelos, estratégias e ferramentas capazes de realizar a detecção automatizada de similaridade do código-fonte (BEJARANO, GARCÍA e ZUREK, 2015; CAMPANA FILHO et al., 2017; FLORES et al., 2015; JHI et al., 2015; KAYA e OZEL, 2015; KERMEK e NOVAK, 2016; LIU, XU e OUYANG, 2015; MACIEL et al., 2012; OHMANN e RAHAL, 2015; TIAN, et al., 2015; WANG, YANG e WANG, 2015).

Os trabalhos destacam que possíveis motivações para a similaridade de código-fonte são:

(1) acesso a código-fonte aberto, que permite a utilização, modificação e a falta de entendimento na redistribuição sob certos tipos de licença, como GPL (General Public License);

(2) projetos cada vez mais complexos e de prazos curtos e custos baixos, exigido pelo meio empresarial;

(3) no meio acadêmico, carência de entendimento do que constitui um plágio, somando-se a isso a riqueza de recursos digitais disponíveis na Internet, o que torna a atividade de "cópia e cola" quase natural; e;

(4) complexidade do desenvolvimento de software, como forma de encurtar o ciclo de desenvolvimento do mesmo.

Como contribuição estes trabalhos empenham-se em apresentar resultados que possam apoiar professores na identificação de indícios de plágio, promover a segurança aos profissionais garantindo suas criações e, chamar atenção para o uso do código-fonte licenciado e a compreensão sobre o conceito de reutilização do código-fonte. Contudo, mais importante do que encontrar código-fonte análogo, principalmente em um ambiente educativo, é compreender as razões que levam a cópia. 
Neste sentido, o estudo longitudinal de Cosma et al. (2017) teve como objetivo identificar a percepção dos estudantes universitários de Computação sobre o plágio do código-fonte, determinar influências do background educacional e compreender a abordagem ao plágio. Os resultados revelaram que, embora conhecedores das ações que constituem o plágio, algumas questões não eram claras para os estudantes. Os autores comentam que é necessário que as instituições reflitam sobre essas questões e reconheçam os esforços para reduzir o plágio do código-fonte. Frisam ainda, que é importante que os educadores informem aos estudantes com clareza e exemplos sobre o plágio, incorporando e reforçando a educação do plágio do código-fonte de forma consistente ao longo do currículo.

Estas pesquisas evidenciam a pertinência do tema e como as investigações têm sido conduzidas pelos grupos de pesquisa na área da Computação. Constata-se que os trabalhos discutem o plágio com estudantes universitários sobre a ótica da detecção, investigação e prevenção do plágio do código-fonte. Analisadas, sugerem que a integridade acadêmica é um valor educacional que precisa ser incorporado ao longo do processo de ensino e aprendizagem.

Para além das justificativas da prática do plágio e das ferramentas produzidas discutidas nos trabalhos relacionados, ressalta-se que o risco é restringir as discussões em construir programas para detectar plágio de programas que construímos, ou seja, código detectando uso indevido de código. A questão vai além da compreensão imediata de plágio e, a preocupação de Cosma et al. (2017) em conhecer a perspectiva do estudante não deixa de ser um alerta meio a tantos outros trabalhos que conduzem suas pesquisas no entendimento do algoritmo. No entanto, o estudo de Cosma et al. (2017) não dá conta do processo da experiência no movimento de cópia e restringe-se a questionar aos estudantes sobre o seu entendimento do conceito de plágio e identificar aspectos do plágio que causam confusão.

\section{A Experiência Web-Busca}

Quanto à experiência Web, pesquisas discutem e observam o movimento de busca condicionada e condicional. Os resultados do estudo realizado por Sparrow, Liu e Wegner (2011), indicam que os participantes lembravam melhor do local do que da identidade de um item em si, o que sugere um processo de adaptação da memória. Quando os participantes não sabiam dar respostas às perguntas, pensavam automaticamente no computador como o lugar para encontrá-las (como gadget). Para os pesquisadores as pessoas não memorizam informações porque confiam no fato de que podem consegui-las com suas habilidades de busca na Internet. Concluem que isto tem relação com o mesmo processo da memória transacional estabelecido nas relações sociais, como contar com alguém para lembrar alguma informação.

Para Fisher, Goddu e Keil (2015) a busca e o sucesso de encontrar informações na Internet podem criar a ilusão de que somos mais bem informados. A auto-avaliação do conhecimento é motivada pelo uso de motores de busca - ferramenta de pesquisa -, o que provoca um efeito inflacionado sobre a auto-estima cognitiva. Os autores sugerem que formamos um sistema similar de memória transacional com a Internet e que as pessoas terceirizam tarefas cognitivas para a Internet se elas sabem como recuperar informações, ou seja, localizar a resposta. No entanto, ressaltam, que mais do que um mero dispositivo de armazenamento externo, as características da Internet de acesso imediato, intermitente e vasta em quantidade de informação especializada (expertise), tornam-na um parceiro de memória transacional ideal.

O estudo de Wang et al. (2017) reafirma que motores de busca da Web servem como fonte de memória externa. De acordo com os autores, informações extremamente acessíveis e as poderosas funções de busca, classificação, facilidade de uso, interface amigável e confiabilidade, podem nos tornar dependentes das ferramentas de pesquisa. Os pesquisadores concluem que estamos expostos a grandes quantidades de informações a cada momento e não podemos converter toda a memória de curto em memória de longo prazo. Entender isto é necessário para compreender como nos adaptamos a um ambiente complexo e desconhecido, onde podemos conseguir os recursos instantaneamente ao invés de lembrar-se de tudo.

Para Wang et al. (2017, p.7) a curiosidade epistêmica aumenta a motivação e a atividade do sistema de memória. Isto desencadeia diferentes níveis de curiosidade e, em seguida, a curiosidade facilita 
o comportamento da pesquisa na Web. Os autores citados diferem da interpretação de Fisher, Goddu e Keil (2015), que relatam que os participantes da pesquisa acreditavam que seus cérebros eram aprimorados depois de buscar informações na Internet. A Web pode ser uma parceira, como fonte de memória externa (Sparrow, Liu e Wegner, 2011), contudo é preciso ter atenção à confusão entre informação e conhecimento, acesso à informação e o próprio entendimento (FISHER, GODDU e KEIL, 2015).

Soma-se a essa discussão o fato de que a riqueza de recursos digitais disponíveis transforma as atividades, de cópia e cola "quase naturais" e a necessidade de compreensão sobre aspectos como a reutilização código-fonte aberto, percebidos apenas como vantagens (FLORES, et al., 2015; KAYA e OZEL, 2015; KERMEK e NOVAK, 2016; OHMANN e RAHAL, 2015; WANG, YANG e WANG, 2015). Como discutido por Cosma et al. (2017), existem questões que ultrapassam a percepção imediata de seus benefícios e da capacidade técnica e implicam em realizar um debate ético.

Porém, faz-se necessário compreender também como o uso da Web mobiliza o processo e a qualidade da experiência, razões que circulam a valorização do movimento de busca como um elemento constante da experiência e das implicações associadas a ele. Portanto, salienta-se problematizar o uso da Web no âmbito da programação pelo seu efeito de importância, relevância, conhecimento e satisfação, como verdadeira fonte de pesquisa. Invertendo a perspectiva do ponto de vista do processo do ato de estudar, da solução imediata até a compreensão, perguntamos: como o estudante entende sua experiência com a Web na resolução de Desafios de Programação de Estrutura de Dados?

\section{METODOLOGIA}

Para conhecer como os estudantes avaliam à experiência com a Web, como espaço de estudo que os apoia na resolução dos Desafios de programação da disciplina de Estrutura de Dados (cabe ressaltar que a turma é formada por estudantes de diferentes semestres), estes foram convidados a responder um questionário com seis perguntas. O desafio trata-se de uma situação-problema que deve ser solucionada atendendo requisitos para o projeto do software. Com base nos dados, discute-se sobre o que os estudantes falam de suas experiências de estudo com a Web quando na resolução de desafios. Esclarecemos que, o foco principal foi conhecer o que os estudantes dizem sobre sua experiência Web na resolução de Desafios de programação, com o propósito de entender se há relação com a preocupação levantada na discussão teórica, identificar possíveis indícios para problematizar e conduzir a caminhada de pesquisa.

Assim, a perspectiva quantitativa do questionário teve por objetivo abranger o maior número de respostas e permitir a replicabilidade do instrumento, quando nas mesmas condições de estudo, e possibilitar certa generalização das respostas obtidas para problematização. Portanto, o objetivo foi sinalizar o entendimento, de forma mais ampla, dos estudantes da disciplina de Estrutura de Dados sobre a experiência da pesquisa com a Web na resolução de Desafios de programação.

\section{Método e Procedimento}

Os estudantes da disciplina de Estrutura de Dados foram convidados a responder ao questionário em três momentos durante dois semestres, todos ao final de cada Desafio de programação. A participação não foi identificada, de forma que não é possível saber se o estudante que respondeu o primeiro questionário, também respondeu os demais. Sobre isto não se teve preocupação em traçar uma linha histórica individual, mas conhecer as respostas no momento em que ocorreram os desafios. As respostas, quando averiguadas em momentos diferentes, apenas podem evidenciar se o andamento da disciplina influencia no uso da Web como apoio na resolução dos Desafios de programação. No entanto, o foco principal com a coleta foi conhecer de que forma os estudantes avaliam o uso da Web para os aspectos analisados no questionário.

O questionário foi criado no site Socrative na versão gratuita. Observadas as limitações, como não permitir configurar resposta obrigatória e não disponibilizar um espaço para observações optou-se por utilizar, a partir do segundo semestre, o Google Forms. A divulgação do questionário 
ocorreu ao final de cada desafio por convite em sala de aula e avisos na sala virtual Blackboard (Ambiente Virtual/Digital de Aprendizagem) da disciplina.

O questionário foi organizado em duas etapas:

(1) apresentação da pesquisa e orientação; e,

(2) questões sobre a experiência Web na resolução do Desafio de programação. Ao acessar o link do questionário, o texto introdutório apresenta informações, orientações, identificação sobre a pesquisa e solicitava que o estudante considerasse apenas o uso da Web na resolução do Desafio de programação.

A preocupação com a ética na pesquisa é ressaltada pelo Termo de Consentimento Livre e Esclarecido que trata da atenção e da preservação de anonimato, garantidos pelas pesquisadoras responsáveis e, cujo aceite, permitiu o prosseguimento da coleta. Ampliando a preocupação com a ética na pesquisa, foi submetida à Carta de Autorização a Apresentação da Pesquisa e aprovada pelo Coordenador de Curso e Comitês de Ética em Pesquisa (Proponente e Coparticipantes) da instituição onde ocorreu a coleta de dados (conforme Plataforma Brasil - CAAE 96223318.7.0000.5347).

$\mathrm{Na}$ segunda etapa do questionário são apresentadas seis questões que tratam dos aspectos: Frequência, Tempo, Avaliação, Relevância, Conhecimento e Recursos (Quadro 1). Sobre estes cabe dar-lhes significado para compreendê-los:

(1) Frequência e (2) Tempo são características difíceis de serem pontuadas porque estamos online quase initerruptamente e nossas pesquisas Web de estudo se misturam e concorrem com diversas outras finalidades. No entanto, para classificar Frequência e Tempo, o estudante pode criar aproximação baseada na sua percepção. Tais questões são importantes como convite à reflexão e indício para entender se o número de acessos manifestados tem correspondência com a quantidade de tempo percebida. Soma-se a isto o fato de que é possível verificar a relação entre estes e os demais aspectos.

(3) Avaliação diz respeito à percepção do estudante quanto à sua satisfação com o resultado de sua pesquisa Web na solução e implementação efetiva do desafio.

(4) Relevância, o mais pertinente aspecto quanto ao significado e reflexão que pode mobilizar, trata de como o estudante percebe a indispensabilidade da pesquisa Web na resolução e implementação do Desafio de programação.

(5) Conhecimento, trata da importância percebida pelo estudante da pesquisa Web na formação do conhecimento e na resolução e implementação do desafio.

(6) Recursos questiona sobre o que auxilia nos estudos. A partir do segundo semestre, esta pergunta passou a ser apresentada em uma lista de opções com base nas respostas mais recorrentes dos estudantes do semestre anterior, como: Web (motor de busca), livro físico, e-books, vídeos e áudios, apresentações, materiais sala virtual, colegas e professores.

\section{Participantes}

A coleta contou com 152 respostas. Utiliza-se a nomenclatura respostas, pois o mesmo estudante pode ter respondido em momentos diferentes. O estudo considerou 149 respostas, uma vez que três (03) respostas foram descartadas por não ter preenchimento completo.

\section{Análise dos dados}

Considerando que este estudo se trata de uma pesquisa quantitativa-qualitativa, as variáveis categóricas foram expressas por frequências absoluta e relativa, e apresentadas por meio de distribuição de frequências. Para a análise conjunta de duas variáveis - análise bivariada - utilizou-se a dupla classificação (BARBETTA, 2008). As análises foram realizadas no Excel 2010 e validadas no SPSS versão 18. 
Quadro 1 - Aspectos da experiência com a Web na resolução do Desafio de programação.

\begin{tabular}{|c|c|c|}
\hline $\begin{array}{l}\text { Aspecto } \\
\text { (variável) }\end{array}$ & Pergunta & Respostas (categorias) \\
\hline Frequência & $\begin{array}{l}\text { Com que frequência você utilizou a Web } \\
\text { como espaço de pesquisa para a resolução e } \\
\text { implementação do problema apresentado } \\
\text { no desafio? }\end{array}$ & $\begin{array}{l}\text { Não utilizei } \\
1 \text { vez } \\
2 \text { vezes } \\
3 \text { vezes } \\
4 \text { vezes ou mais }\end{array}$ \\
\hline Tempo & $\begin{array}{l}\text { Em média, para resolver e implementar o } \\
\text { desafio, quanto tempo você estima que } \\
\text { dedicou somente à pesquisa na Web? }\end{array}$ & $\begin{array}{l}\text { Não utilizei } \\
1 \text { hora } \\
2 \text { horas } \\
3 \text { horas } \\
4 \text { horas ou mais }\end{array}$ \\
\hline Avaliação & $\begin{array}{l}\text { Como você avalia o resultado da pesquisa } \\
\text { Web na solução e implementação efetiva do } \\
\text { desafio? }\end{array}$ & $\begin{array}{l}\text { Não estou satisfeito } \\
\text { Pouco satisfeito } \\
\text { Satisfeito } \\
\text { Muito satisfeito }\end{array}$ \\
\hline Relevância & $\begin{array}{l}\text { Sem o acesso e a pesquisa a Web, você } \\
\text { acredita que }\end{array}$ & $\begin{array}{l}\text { seria improvável resolver e implementar o } \\
\text { desafio } \\
\text { seria pouco provável que eu conseguisse } \\
\text { resolver e implementar } \\
\text { nem improvável, nem provável } \\
\text { seria muito provável que eu conseguisse } \\
\text { resolver e implementar } \\
\text { é certo que eu conseguiria resolver e } \\
\text { implementar o desafio }\end{array}$ \\
\hline Conhecimento & $\begin{array}{l}\text { No geral, qual a importância da pesquisa } \\
\text { Web na formação do seu conhecimento e } \\
\text { na resolução de problemas de } \\
\text { implementação? }\end{array}$ & $\begin{array}{l}\text { Nada importante } \\
\text { Pouco importante } \\
\text { Importante } \\
\text { Muito importante }\end{array}$ \\
\hline Recursos & $\begin{array}{l}\text { No geral, qual(is) recurso(s) lhe auxilia(m) } \\
\text { mais nos estudos }\end{array}$ & $\begin{array}{l}\text { Resposta aberta (primeiro semestre) } \\
\text { Opções indicadas por estudantes do primeiro } \\
\text { semestre (segundo semestre) }\end{array}$ \\
\hline
\end{tabular}

\section{Resultados}

Os resultados descritivos encontrados sobre a Frequência indicam que 44,3\% (66) das respostas manifestam que os estudantes utilizam 4 vezes ou mais a Web como espaço de pesquisa para apoio na resolução e implementação do Desafio de programação; 22,1\% (33) indicam frequência de 2 vezes; 16,8\% (25) pontuam 3 vezes; 10,1\% (15) manifestam 1 vez; 6,7\% (10) declaram não ter utilizado a Web. Quanto ao aspecto Tempo, os resultados descritivos encontrados indicam que 31,5\% (47) das respostas relatam que os estudantes estimam dedicar 1 hora à pesquisa Web; 25,5\% (38) manifestam 2 horas; 21,5\% (32) anunciam 4 horas ou mais; 12,1\% (18) estimam 3 horas de dedicação; e, 9,4\% (14) declaram não ter utilizado.

Para o aspecto Avaliação, 57\% (85) das respostas anunciam que os estudantes estão satisfeitos com os resultados da pesquisa na Web para a resolução e implementação do Desafio de programação; 27,5\% (41) mostram-se pouco ou não satisfeitos; e 15,4\% (23) declaram estar muito satisfeitos. Importante salientar que as categorias "Pouco satisfeito" e "Não estou satisfeito" foram agrupadas e explicar que, mesmo aqueles estudantes que manifestam "Não utilizei" para os aspectos de Tempo e Frequência, responderam este item Avaliação.

Sobre o aspecto Relevância, 35,6\% (53) das respostas retratam que os estudantes manifestam que seria muito provável ou é certo que conseguiriam resolver e implementar o Desafio de programação sem o acesso e a pesquisa na Web; 33,6\% (50) das respostas indicam que seria pouco provável ou improvável resolver e implementar; e 30,9\% (46) manifestam a resposta "nem improvável, nem provável". As categorias "seria improvável resolver e implementar o desafio" e "seria pouco provável que eu conseguisse resolver e implementar" foram agrupadas, assim como "seria muito 
provável que eu conseguisse resolver e implementar" e "é certo que eu conseguiria resolver e implementar o desafio".

Quanto ao aspecto Conhecimento, 51,0\% (76) das respostas mostram que os estudantes consideram a pesquisa na Web importante para a formação do conhecimento e na resolução de problemas de implementação; 34,2\% (51) acreditam ser muito importante; e 14,8\% (22) afirmam ser pouco ou nada importante. As categorias "Pouco importante" e "Nada importante" foram agrupadas.

No que tange ao aspecto Recursos, os resultados indicam que: $24,4 \%$ Web (motores de busca); $21,7 \%$ colegas e professores; $21,7 \%$ vídeos e áudios; $15,4 \%$ materiais disponibilizados na sala virtual; 7,2\% livro físico; 7,2\% e-book; e, 2,3\% apresentações. A maior parte declara que o principal recurso de auxílio nos estudos são os motores de busca, de forma que reforçam a importância que atribuem às questões anteriores sobre o uso da Web, principalmente das ferramentas de pesquisa.

Para profundar a discussão sobre os aspectos Avaliação, Relevância e Conhecimento, realizou-se a associação do conjunto de elementos através da análise de duas variáveis qualitativas análise bivariada -, para investigar os aspectos Relevância-Avaliação, Relevância-Conhecimento e Avaliação-Conhecimento. A análise das respostas associadas entre satisfação, indispensabilidade e importância, permitiu esboçar considerações sobre a experiência com a Web e a utilidade na resolução de problemas de programação.

A Tabela 1 mostra os resultados da análise da distribuição conjunta das variáveis AvaliaçãoRelevância. Para a situação de "Pouco provável ou improvável", 60,0\% das respostas manifestam estar satisfeito com o resultado da pesquisa na Web; soma-se à situação de satisfação 56,5\% das repostas que indicam "Nem improvável, nem provável". Isto implica que, aproximadamente, $54,7 \%$ das respostas dos participantes satisfeitos afirmam que muito provavelmente conseguiriam solucionar o desafio sem o acesso e a pesquisa Web.

Tabela 1 - Distribuição da Relevância pela Avaliação.

\begin{tabular}{|c|c|c|c|c|}
\hline \multirow[b]{2}{*}{ Avaliação } & \multicolumn{3}{|c|}{ Relevância } & \multirow[b]{2}{*}{ Total } \\
\hline & $\begin{array}{c}\text { Pouco provável ou } \\
\text { improvável }\end{array}$ & $\begin{array}{c}\text { Nem improvável, } \\
\text { nem provável }\end{array}$ & $\begin{array}{l}\text { Muito provável ou } \\
\text { certo que }\end{array}$ & \\
\hline Pouco ou não satisfeito & $11(22,0)$ & $15(32,6)$ & $15(28,3)$ & $41 \quad(27,5)$ \\
\hline Satisfeito & $30(60,0)$ & $(56,5)$ & $29 \quad(54,7)$ & $85 \quad(57,0)$ \\
\hline Muito satisfeito & $9(18,0)$ & $5(10,9)$ & $9(17,0)$ & $23(15,4)$ \\
\hline Total & $50(100,0)$ & $46(100,0)$ & $53(100,0)$ & $149(100,0)$ \\
\hline
\end{tabular}

NOTA: Os números entre parênteses são percentagens em relação aos totais das colunas.

A Tabela 2 mostra os resultados da análise da distribuição conjunta das variáveis Conhecimento-Relevância. Ressalta-se que, para a situação "Pouco provável ou improvável", 58\% das respostas revelam ser muito importante a pesquisa Web na formação do seu conhecimento e na resolução de problemas de implementação. Considerando importante, para a situação "Nem improvável, nem provável" e "Muito provável ou é certo que", o resultado foi de $63 \%$ e $60,4 \%$, respectivamente. Níveis maiores de importância são manifestados por aquele grupo que apontam ser improvável ou pouco provável conseguir resolver o desafio sem o acesso e a pesquisa na Web.

Tabela 2 - Distribuição da Relevância pela importância na formação do Conhecimento.

\begin{tabular}{|c|c|c|c|c|}
\hline \multirow[b]{2}{*}{ Conhecimento } & \multicolumn{3}{|c|}{ Relevância } & \multirow[b]{2}{*}{ Total } \\
\hline & $\begin{array}{c}\text { Pouco provável ou } \\
\text { improvável }\end{array}$ & $\begin{array}{c}\text { Nem improvável, } \\
\text { nem provável }\end{array}$ & $\begin{array}{l}\text { Muito provável ou } \\
\text { certo que }\end{array}$ & \\
\hline Pouco ou nada importante & $6(12,0)$ & $6(13,0)$ & $10(18,9)$ & $22(14,8)$ \\
\hline Importante & $15(30,0)$ & $29 \quad(63,0)$ & $32(60,4)$ & $76(51,0)$ \\
\hline Muito importante & $29 \quad(58,0)$ & $11(23,9)$ & $11(20,8)$ & $51 \quad(34,2)$ \\
\hline Total & $50 \quad(100,0)$ & $46(100,0)$ & $53(100,0)$ & $149(100,0)$ \\
\hline
\end{tabular}

NOTA: Os números entre parênteses são percentagens em relação aos totais das colunas. 
A Tabela 3 apresenta a análise da distribuição conjunta das variáveis ConhecimentoAvaliação. Com relação à satisfação, $57,6 \%$ das respostas que consideram a situação de "Satisfeito" com o resultado da pesquisa Web também declaram ser ela importante. Para a categoria "Muito satisfeito", $60,9 \%$ das respostas revelam ser a pesquisa muito importante na formação do seu conhecimento. Consideram mais importante o acesso e a pesquisa Web os grupos que apontam estar satisfeitos ou muito satisfeitos com o resultado da pesquisa na solução e implementação do desafio.

Tabela 3 - Distribuição da Avaliação pela importância na formação do Conhecimento.

\begin{tabular}{|c|c|c|c|c|}
\hline \multirow[b]{2}{*}{ Conhecimento } & \multicolumn{3}{|c|}{ Avaliação } & \multirow[b]{2}{*}{ Total } \\
\hline & $\begin{array}{c}\text { Pouco ou não } \\
\text { satisfeito }\end{array}$ & Satisfeito & Muito satisfeito & \\
\hline Pouco ou nada importante & $14(34,1)$ & $7 \quad(8,2)$ & $(4,3)$ & $22(14,8)$ \\
\hline Importante & $19(46,3)$ & $49 \quad(57,6)$ & $8(34,8)$ & $76 \quad(51,0)$ \\
\hline Muito importante & $8 \quad(19,5)$ & $29(34,1)$ & $14(60,9)$ & $51 \quad(34,2)$ \\
\hline Total & $41 \quad(100,0)$ & $85(100,0)$ & $23(100,0)$ & $149(100,0)$ \\
\hline
\end{tabular}

NOTA: Os números entre parênteses são percentagens em relação aos totais das colunas.

\section{DISCUSSÃO DOS RESULTADOS}

Para a discussão dos dados obtidos e análises descritivas estatísticas apresentadas, observase que quanto ao aspecto Frequência, 44,3\% das respostas mostram a escolha pela opção no nível mais alto, de forma que a maioria manifestou utilizar a Web como espaço de pesquisa por "4 vezes ou mais" durante a resolução e implementação do desafio. Por outro lado, no tocante ao Tempo, nota-se que a opção dos estudantes está associada a níveis mais baixos de tempo, pois 31,5\% das respostas estimam 1 hora de uso dedicada à pesquisa. Níveis mais altos de frequência para níveis mais baixos de tempo podem demonstrar confusão ou dificuldade em mensurar o período de tempo dedicado à Web.

Analisando o cruzamento entre a questão do período de tempo dedicado e a variedade de acessos contínuos, identifica-se um hábito, imerso em estímulos externos, que busca certa rapidez. Isto pode gerar a incapacidade de desenvolver a experiência e o controle de suas características que permitam reconhecer a qualidade do processo, principalmente quando o foco está direcionado para o aumento da destreza das atividades automáticas (DEWEY, 1976, 1978, 1980). Neste sentido, ainda, pode-se dizer que o hábito, dirigido pela conexão e os seus traços eficientes e rápidos de agir, buscam obter como resultado a economia de tempo e o esforço para atingir o que se procura (CUPANI, 2013). De certa forma, os resultados corroboram o estudo de Fisher, Goddu e Keil (2015), quando trata das características da Internet vistas como positivas e vantajosas de acesso imediato, intermitente e uma vasta quantidade de informação.

Também se reconhecem, nesta relação, menor espaço de tempo e maior variedade de acessos contínuos, possibilidades de implicações na condição da pesquisa realizada. Embora não se tenha elementos suficientes para discorrer sobre o caráter da qualidade dos acessos, visto a natureza de nossos dados quantitativos, podemos sinalizar que o acesso ocorre de forma fragmentada - com frequência maior para vários acessos (LARROSA, 2002). Prematuramente, isto pode levar ao entendimento de que o motor da resolução de um problema está no ato de saber buscar de forma "eficiente", ou seja, em menor tempo (FISHER; GODDU; KEIL, 2015). O fato de manifestar o uso da Web várias vezes, como espaço de pesquisa para a resolução e implementação do problema de programação, pode fazer com que o estudante tenha foco em aprimorar suas habilidades de busca (SPARROW; LIU; WEGNER, 2011). Desta forma, a avaliação do processo realizado em uma pesquisa e a qualidade da informação encontrada na busca, pode ser levada pela circunstância da maior importância dedicada ao desenvolvimento de habilidades técnicas de busca (CUPANI, 2013).

Sobre os aspectos Avaliação, Relevância e Conhecimento, estes fornecem indicativos da percepção do estudante quanto à pesquisa Web na resolução de Desafios de programação em termos de 
satisfação, indispensabilidade e importância. Nota-se que 57\% das respostas dos estudantes avaliam estar satisfeitos com o resultado da pesquisa Web, soma-se a este 15,4\% que estão muito satisfeitos. A maioria das respostas, $51 \%$ sugerem ser importante a pesquisa Web na formação do conhecimento e na resolução de problemas de implementação, acrescenta-se 34,2\% que apontam ser muito importante. No entanto, quanto à relevância, não é possível identificar uma concentração das respostas em um dos itens, pois estão distribuídas de forma equilibrada entre 35,6\% "muito provável ou é certo que conseguiria resolver e implementar o desafio"; 33,6\% "pouco provável ou improvável resolver e implementar o desafio"; e 30,9\% “nem improvável, nem provável”.

Com base nas análises para investigar os aspectos Relevância-Avaliação, RelevânciaConhecimento e Avaliação-Conhecimento, os dados demonstram indícios da questão apresentada nesse estudo e mobilizam o problema de pesquisa. Do ponto de vista pragmático sabemos que estudantes buscam na Web soluções para resolver seus problemas de programação. É fato que os estudantes também prenunciam a importância e relevância deste mecanismo como verdadeira fonte de pesquisa, conhecimento e satisfação, principalmente quando revelam depender da Web para chegar à solução do problema de programação. Este resultado é reforçado quando ao elencar os recursos, escolhem novamente a Web e motores de busca como principal apoio nos estudos.

A análise das respostas revela o valor que o estudante atribui à sua experiência com a Web, sendo manifestas a avaliação positiva e a satisfação com o resultado da pesquisa. Também é reconhecida a importância da Web na formação do conhecimento e na resolução de problemas de programação. Portanto, a Web pode trazer implicações ao processo e, consequentemente, na qualidade da experiência (DEWEY, 1976, 1978, 1980). Constata-se assim, que a satisfação e a importância afetam o caráter da experiência, quando orientadas pela causa, e são elementos que podem conduzir a situação como agradável. Nessa direção, quanto maior ênfase for atribuída ao meio e ao significado funcional da escolha dos resultados apresentados, mais útil pode se tornar a ferramenta. Desta forma, faz-se necessário atentar para o hábito imerso em estímulos e pautado na preferência, pois pode afetar o processo e a qualidade da experiência (CUPANI, 2013; DEWEY, 1976, 1978, 1980; LARROSA, 2002, 2018; MCLUHAN, 1964, 1977).

Embora identificada à relação dos aspectos abordados neste estudo com a experiência positiva da Web manifestada pelos estudantes, não podemos oferecer os motivos para isto, visto a natureza limitada dos dados quantitativos. Por outro lado, conhecendo os resultados, cabe argumentar que é preciso evitar que tais características orientem atitudes descuidadas, atenção mal dirigida e mal disciplinada, dispersa e pouco concentrada ou, ainda, que influenciem no processo da experiência, como modo repetitivo de enfrentar as situações futuras (DEWEY, 1976, 1978, 1980; LARROSA, 2002, 2018). Imerso nessas condições, o que se sabe, apontado por Wang et al. (2017), é a necessidade de maior controle de impulsos e de esforços para resistir às distrações.

\section{CONSIDERAÇÕES FINAIS}

Este artigo apresentou o estudo sobre a percepção dos estudantes universitários de Computação sobre a sua experiência Web na resolução de Desafios de Programação de Estrutura de Dados. Constatou-se a relevância da pesquisa Web, pontuada pelos estudantes, a partir da visão afirmativa que fazem do uso, a importância que eles atribuem e a satisfação que manifestam. Deste modo, a Web se torna indispensável parceira para conseguir enfrentar um problema de programação. Contudo, este processo pode configurar um paradigma e um envolvimento maior com o meio do que com o próprio problema a ser resolvido. Isto pode afetar elementos da experiência, como atribuir maior valor à relação técnica produtiva que se estabelece com a Web (CUPANI, 2013; FISHER; GODDU; KEIL, 2015; SPARROW; LIU; WEGNER, 2011; MCLUHAN, 1964, 1977; WANG et al. , 2017).

A construção deste entendimento parte da costura e da compreensão do nosso objeto de estudo, a partir de uma elaboração crítica, mobilizada em direção da experiência e da reflexão da natureza de operação do meio (CUPANI, 2013; DEWEY, 1976, 1978, 1980; LARROSA, 2002, 2018; MCLUHAN, 1964, 1977). Seguimos a pesquisa por caminhos distintos daqueles que a Computação e os trabalhos apresentados na seção que trata da Autoria-Cópia deste artigo nos oferecem, com seus 
algoritmos de detecção ou do entendimento do conceito plágio e aspectos que podem causar confusão. Colocamos em pauta o processo e a relação com o meio, entendendo a influência de nossas ferramentas, como discutido na seção Experiência Web-Busca.

Se ao resolver os Desafios de programação o estudante recorrer à pesquisa Web como recurso e, também entender que seu afastamento dela por vezes é importante, poderá ele olhar a situação de forma ativa. Saberá, portanto, no momento certo, como neutralizar alguns efeitos e potencializar outros. Do outro lado, se o professor entender o processo desta experiência, estará seguro sobre como lidar com as condições objetivas da situação. A educação e a informática têm responsabilidades compartilhadas. Para além do software, do hardware e de qualquer outro dispositivo, nossa atenção deve voltar-se, também, a tecnologia em uso como forma de estudo e natureza de operação.

Podemos afirmar que, na relação com a Web e em processo da experiência, entre resolver um problema e o desfecho da solução, buscada ou apoiada pela Web, o efeito do meio aparece como benefício, em oposição ao enfrentamento do problema sem ela. Assim, a avaliação positiva e a relevância da Web para o processo de resolução de problemas de programação mobilizam a continuidade da pesquisa no sentido de procurar compreender, em estudos futuros, as implicações desta experiência para estudantes de Estrutura de Dados. Portanto, segue-se o caminho de pesquisa no esforço por esclarecer por que os estudantes valorizam a busca e trazer contribuições para a comunidade acadêmica dos cursos de Computação, especificamente para a área de programação, instituição, professor e estudantes. Os resultados levantados animam a discussão e a compreensão da experiência, e deste modo também conduzem a reflexão da prática e a orientação na direção do desenvolvimento consciente, tanto no aspecto da reflexão crítica, quanto do processo metodológico e pedagógico com a Web.

\section{REFERÊNCIAS}

BANNELL, R. I. Uma faca de dois gumes. In: Ferreira, G. M. S.; Rosado, L. A. S.; Carvalho, J. S. (Orgs.). Educação e Tecnologia: abordagens críticas. Rio de Janeiro: SESES, 2017, p. 17-51.

BARBETTAA, P. A. Estatística aplicada às Ciências Sociais. 7ed. Florianópolis: Ed. da UFSC, 2008.

BEJARANO, A. M.; GARCÍA, L. E.; ZUREK, E. E. Detection of source code similitude in academic environments. Computer Applications in Engineering Education, [s. 1.], v. 23, n. 1, p. 13-22, 2015.

CAMPANA FILHO, J. C.; OLIVEIRA, E.; OLIVEIRA, M. G.; NOGUEIRA, M. Detecção de Suspeita de Plágio de Códigos C para Apoio ao Ensino em Programação. Anais do Computer on the Beach. Florianópolis: Universidade do Vale do Itajaí, p. 436-445, 2017.

COSMA, G.; JOY, M.; SINCLAIR, J.; ANDREOU, M.; ZHANG, D.; COOK, B.; BOYATT, R. Perceptual Comparison of Source-Code Plagiarism within Students from UK, China, and South Cyprus Higher Education Institutions. ACM Transactions on Computing Education (TOCE), [s. 1.], v. 17, n. 2, Article 8, p. 1-16, 2017.

CUPANI, A. Filosofia da tecnologia: um convite. 2ed., Florianópolis: Ed. UFSC, 2013.

DEWEY, J. Experiência e educação./tradução Anísio Teixeira. 2ed., São Paulo: Ed. Nacional, 1976.

DEWEY, J. Vida e educação./tradução Anísio S. Teixeira. 10ed., São Paulo: Melhoramentos; Rio de Janeiro: Fundação Nacional de Material Escolar, 1978.

DEWEY, J. Experiência e natureza; Lógica: a teoria da investigação; A arte como experiência; Vida e educação; Teoria da vida moral./ tradução Murilo Otávio Rodrigues Paes Leme, Anísio S. Teixeira, Leônidas Gontijo de Carvalho. São Paulo: Abril Cultural, 1980. 318 p. (Os pensadores). 
FISHER, M.; GODDU, M. K; KEIL, F. C. Searching for explanations: How the Internet inflates estimates of internal knowledge. Journal of Experimental Psychology: General, [s. 1.], v. 144, n. 3, p. 674-687, 2015.

FLORES, E.; BARRÓN-CEDEÑO, A.; MORENO, L.; ROSSO, P. Uncovering source code reuse in large-scale academic environments. Computer Applications in Engineering Education, [s. 1.], v. 23, n. 3, p. 383-390, 2015.

JHI, Y.; JIA, X.; WANG, X.; ZHU, S.; LIU, P.; WU, D. Program Characterization Using Runtime Values and Its Application to Software Plagiarism Detection. IEEE Transactions on Software Engineering, [s. 1.], v. 41, n. 9, p. 925-943, 2015.

KAYA, M.; OZEL, S. A. Integrating an online compiler and a plagiarism detection tool into the Moodle distance education system for easy assessment of programming assignments. Computer Applications in Engineering Education, [s. 1.], v. 23, n. 3, p. 363-373, 2015.

KERMEK, D.; NOVAK, M. Process Model Improvement for Source Code Plagiarism Detection in Student Programming Assignments. Informatics in Education, [s. 1.], v. 15, n. 1, p. 103-126, 2016.

LARROSA, J. B. Notas sobre a experiência e o saber de experiência. Revista Brasileira de Educação, [s. 1.], n. 19, p. 20-28, 2002.

LARROSA, J. B. Esperando não se sabe o quê: sobre o ofício de professor. Belo Horizonte: Autêntica Editora, 2018.

LIU, X.; XU, C.; OUYANG, B. Plagiarism Detection Algorithm for Source Code in Computer Science Education. International Journal of Distance Education Technologies, [s. 1.], v. 13, n. 4, p. 29-39, 2015.

MACIEL, D. L.; SOARES, J. M.; FRANÇA, A. B.; GOMES, D. G. Análise de similaridade de códigosfonte como estratégia para o acompanhamento de atividades de laboratório de programação. RENOTE - Revista Novas Tecnologias na Educação, [s. 1.], v. 10, n. 3, 2012.

MCLUHAN, M. Os meios de comunicação: como extensões do homem. 4ed. São Paulo: Cultrix, 1964.

MCLUHAN, M. The medium is the message. In: Mondey Conference on ABC Radio National, 27 June 1977, ABC News (Australia), 30 jun. de 2011. Disponível em: <https://youtu.be/1YZzwvjwiLs>. Acesso em: 02 nov. 2019.

OHMANN, T.; RAHAL, I. Efficient clustering-based source code plagiarism detection using PIY. Knowledge and Information Systems, [s. 1.], v. 43, n. 2, p. 445-472, 2015.

POWERS, W. O BlackBerry de Hamlet: uma filosofia prática para viver bem na era digital./tradução Daniel Abrão. São Paulo: Alaúde Editorial, 2012.

SOARES, R. O.; BAGATINI, D. D. S.; REATEGUI, E. B.; BIASUZ, M. C. V.; ZAFFARONI, F. Uso da Internet por Estudantes Universitários: um Campo de Estudo Emergencial. RENOTE - Revista Novas Tecnologias na Educação, [s. 1.], v. 17, n. 2, p. 1-11, 2018.

SPARROW, B.; LIU, J.; WEGNER, D. M. Google effects on memory: cognitive consequences of having information at our fingertips. Science (New York, N.Y.), [s. 1.], v. 333, n. 6043, p. 776-778, 2011. 
TIAN, Z.; ZHENG, Q.; LIU, T.; FAN, M.; ZHUANG, E.; YANG, Z. Software Plagiarism Detection with Birthmarks Based on Dynamic Key Instruction Sequences. IEEE Transactions on Software Engineering, [s. 1.], v. 41, n. 12, p. 1217-1235, 2015.

WANG, Y.; WU, L.; LUO, L.; ZHANG, Y.; DONG, G. Short-term Internet search using makes people rely on search engines when facing unknown issues. PLoS One, [s. 1.], v. 12, n. 4, 2017.

WANG, B.; YANG, X.; WANG, G. Detecting Copy Directions among Programs Using Extreme Learning Machines. Mathematical Problems in Engineering, [s. 1.], v. 2015, 2015.

Submetido: $11 / 10 / 2019$

Aprovado: $14 / 09 / 2020$ 